\title{
Mesolimbic Dopamine in Desire and Dread: Enabling Motivation to Be Generated by Localized Glutamate Disruptions in Nucleus Accumbens
}

\author{
Alexis Faure, Sheila M. Reynolds, Jocelyn M. Richard, and Kent C. Berridge \\ Department of Psychology, University of Michigan, Ann Arbor, Michigan 48109-1109
}

\begin{abstract}
An important issue in affective neuroscience concerns the role of mesocorticolimbic dopamine systems in positive-valenced motivation (e.g., reward) versus negative-valenced motivation (e.g., fear). Here, we assessed whether endogenous dopamine receptor stimulation in nucleus accumbens contributes to both appetitive behavior and fearful behavior that is generated in keyboard manner by local glutamate disruptions at different sites in medial shell. 6,7-Dinitroquinoxaline-2,3(1H,4H)-dione (DNQX) microinjections (450 ng) locally disrupt glutamate signals in $<4 \mathrm{~mm}^{3}$ of nucleus accumbens, and generate either desire or fear (or both) depending on precise rostrocaudal location in medial shell. At rostral shell sites, local AMPA/kainate blockade generates positive ingestive behavior, but the elicited motivated behavior becomes incrementally more fearful as the same microinjection is moved caudally. A dopamine-blocking mixture of $\mathrm{D}_{1}$ and $\mathrm{D}_{2}$ antagonists (raclopride and SCH-23390 [ $R(+$ +)-7-chloro-8-hydroxy-3-methyl-1-phenyl-2,3,4,5,-tetrahydro-1H-3-benzazepine hydrochloride]) was combined here in the same microinjection with DNQX to assess the role of endogenous local dopamine in mediating the DNQX-motivated behaviors. We report that local dopamine blockade prevented DNQX microinjections from generating appetitive behavior (eating) in rostral shell, and equally prevented DNQX from generating fearful behavior (defensive treading) in caudal shell. We conclude that local dopamine is needed to enable disruptions of corticolimbic glutamate signals in shell to generate either positive incentive salience or negative fearful salience (valence depending on site and other conditions). Thus, dopamine interacts with localization of valence-biased glutamate circuits in medial shell to facilitate keyboard stimulation of both appetitive and fearful motivations.
\end{abstract}

Key words: dopamine; nucleus accumbens; motivation; glutamate; appetitive behavior; defensive behavior

\section{Introduction}

It is important to understand how mesocorticolimbic mechanisms generate positive versus negative motivations. Dopamine (DA) in the nucleus accumbens is well known as a mechanism of appetitive motivation for reward (Berridge and Robinson, 1998; Kalivas and Volkow, 2005; Wise, 2006; Palmiter, 2007; Robbins and Everitt, 2007; Salamone et al., 2007; Schultz, 2007). However, aversive motivations such as pain, stress, and fear also may involve dopamine in nucleus accumbens (at least tonic dopamine signals) (Blackburn et al., 1992; Salamone et al., 1994, 2005; Redgrave et al., 1999; Horvitz, 2000; Levita et al., 2002; Jensen et al., 2003; Lawrence et al., 2007; Scott et al., 2007; Ventura et al., 2007).

Disruption of glutamate inputs (or local GABA signals) to local circuits in the nucleus accumbens generates both positive

Received Nov. 5, 2007; revised May 6, 2008; accepted May 23, 2008.

This work was supported by National Institutes of Health Grants MH63649 and DA15188. We thank Michelle DiMondo and Phil Hoberg for histology assistance, and Terry Robinson and Jakub Jedynak for microscope access and assistance.

Correspondence should be addressed to Alexis Faure, Department of Psychology, University of Michigan, Ann Arbor, Ml 48109-1109. E-mail: afaure@umich.edu.

A. Faure's present address: Centre National de la Recherche Scientifique, UMR 8620, Université Paris Sud, 91405 Orsay, France.

DOI:10.1523/JNEUROSCI.4961-07.2008

Copyright $\odot 2008$ Society for Neuroscience $\quad$ 0270-6474/08/287184-09\$15.00/0 reward motivation and negative fear motivation, but localized along a keyboard-type rostrocaudal gradient in medial shell (Basso and Kelley, 1999; Stratford and Kelley, 1999; Reynolds and Berridge, 2001, 2002, 2008). Microinjections of a glutamate AMPA antagonist or $\mathrm{GABA}_{\mathrm{A}}$ agonist in rostral shell increase appetitive behavior such as eating, and establish conditioned place preferences. In contrast, as sites become more caudal, microinjections of the same agents establish conditioned place avoidance and incrementally increase fearful reactions such as distress vocalizations and defensive treading (Reynolds and Berridge, 2001, 2002, 2003). Defensive treading is a instinctive behavior of many rodents, which in the wild can entail kicking sand at predator snakes, and in the lab involves quantifiable burying of noxious objects, building mounds, and kicking sand toward experimenters, shock prods, or other perceived threats (Coss and Owings, 1978; Treit et al., 1981).

Mesolimbic dopamine systems interact with glutamate signals to the nucleus accumbens that arise from sources in prefrontal cortex, hippocampus, basolateral amygdala, and thalamus (Groenewegen et al., 1980; Sesack et al., 1989; Everitt et al., 1991; McDonald, 1991; Wright and Groenewegen, 1995; Mulder et al., 1998; Meredith, 1999; Cardinal et al., 2002). Dopamine synapses connect on dendritic spines beneath glutamate synapses, and dopamine modulates the impact of glutamate signals in nucleus accumbens in complex ways (Sesack and Pickel, 1990, 1992). 
Conversely, glutamate modulates dopamine release in nucleus accumbens (Chesselet, 1984; Surmeier et al., 2007).

Tonic dopamine has been suggested to be a neurobiological modulator of information carried by other signals, including glutamate (Chuhma et al., 2004; Grace et al., 2007; Schultz, 2007; Surmeier et al., 2007). Modulation of input signals is compatible with the functional hypothesis that accumbens dopamine modulates glutamate contributions to the attribution of motivational salience to mesocorticolimbic representations of environmental stimuli (Berridge and Robinson, 1998; Kapur, 2003; Berridge, 2007; Palmiter, 2007; Robbins and Everitt, 2007). Here, we tested the hypothesis that local dopamine mediates both incentive salience and fearful salience stimulated by AMPA blockade at appropriate locations in medial shell. We tested whether combined dopamine blockade of $D_{1}$ and $D_{2}$ receptors at the same microinjection site would (1) prevent local AMPA disruption from generating fearful defensive treading behavior in caudal shell, and (2) prevent generation of appetitive eating behavior in rostral shell.

\section{Materials and Methods}

Experiment design. Regions of medial shell responsible for microinjection effects on fear versus feeding behavior were mapped with a Fos plume tool using a design that compared behavioral and neurobiological effects of drug microinjections at equivalent sites. 6,7-Dinitroquinoxaline2,3(1 H,4 H)-dione (DNQX) microinjections produce local plumes of Fos protein translation in nearby neurons (Reynolds and Berridge, 2008), which could be a marker of the same neuronal changes triggered by receptors that mediate behavioral consequences of the drug microinjection, or a compensatory response to those changes in the same neurons, or an indirect marker via drug-induced modulation of adjacent neurons within a local circuit. Regardless, Fos plumes provide an index of the spread and intensity of drug impact on local neural tissue that can be used with microinjections to map localization of function. After surgery, rats were assigned to either behavioral test or Fos plume groups. Both groups were treated identically for their subsequent first microinjection, and then split and assessed for either Fos plumes or behavioral effects. Our goal was to assess maximal effects of DNQX microinjections on both Fos plumes and behavior under similar conditions.

Animals. Sprague Dawley rats [male, 280-350 g at surgery; $n=65$ (behavioral testing, $n=41$; Fos plume, $n=24$ )] were housed on a $12 \mathrm{~h}$ light/dark reverse cycle $\left(\sim 21^{\circ} \mathrm{C}\right)$ with ad libitum access to food (Purina Rat Chow) and water (tap water). All experimental procedures were approved by the animal use office of the University of Michigan.

Microinjection cannula surgery. Rats were implanted with bilateral stainless-steel guide cannulas at coordinates staggered across rats so that the group placements filled the entire medial shell $(n=35$; individual placements were always bilaterally symmetrical). Rostral shell placements were centered around coordinates anteroposterior (AP) +3.4 $\mathrm{mm}$, mediolateral (ML) $\pm 0.9 \mathrm{~mm}$, and dorsoventral (DV) $-5.7 \mathrm{~mm}$ to bregma, whereas caudal shell placements were centered around AP +2 $\mathrm{mm}, \mathrm{ML} \pm 1 \mathrm{~mm}$, and DV $-5.7 \mathrm{~mm}$. Rats were anesthetized with ketamine $(80 \mathrm{mg} / \mathrm{kg})$, xylazine $(5 \mathrm{mg} / \mathrm{kg})$, pretreated with atropine $(0.04$ $\mathrm{mg} / \mathrm{kg}$ ), and positioned in a stereotaxic apparatus (David Kopf Instruments). Chronic bilateral microinjection guide cannulas (23 gauge, stainless steel) were implanted $2 \mathrm{~mm}$ above target sites in the NAc shell (Paxinos and Watson, 2004). A slanted skull position was used to avoid penetrating the lateral ventricles, with incisor bar set at $5.0 \mathrm{~mm}$ above intra-aural zero. Additional anatomical control placements $(n=6)$ were placed in rostrodorsal structures, essentially along cannula tracks projecting to medial shell, in the cortex and lateral septum. All guide cannulas were anchored to the skull with four bone screws and acrylic cement, and stainless-steel obturators were inserted in guide cannulas to prevent occlusion. Each rat received prophylactic penicillin (aquacillin; 45,000 U, i.m.). After surgery, rats were allowed to recover for at least $7 \mathrm{~d}$ before testing.

Drugs and intracerebral microinjections. Fear versus feeding motivation was induced by a localized disruption of glutamate transmission at dif- ferent rostrocaudal positions in the medial shell. The role of endogenous dopamine was assessed by local blockade of dopamine $D_{1} / D_{2}$ in the same microinjection. Three different drug microinjection conditions were used for each rat in the primary test group $(n=23)$, presented in counterbalanced order, as the primary test of dopamine's role in enabling DNQX-elicitation of fear versus feeding. One microinjection condition contained the AMPA/kainate glutamate receptor antagonist, DNQX (Sigma; $450 \mathrm{ng}$ dissolved in $0.5 \mu \mathrm{l} 50 \% \mathrm{DMSO} / 50 \% 0.15 \mathrm{M}$ saline; a moderately high dose of $450 \mathrm{ng}$ was chosen to ensure robust elicitation of fear and feeding behaviors based on a previous experiment) (Reynolds and Berridge, 2003). A second microinjection condition contained a "glutamate-dopamine antagonist mixture": a single microinjection that included both DNQX (450 ng/0.5 $\mu \mathrm{l})$ along with a mixture of the selective $\mathrm{D}_{2}$ dopamine antagonist (raclopride, $5 \mu \mathrm{g} / 0.5 \mu \mathrm{l}$ ) and selective $\mathrm{D}_{1}$ antagonist $\quad[R(+)$-7-chloro-8-hydroxy-3-methyl-1-phenyl-2,3,4,5,tetrahydro-1 $H$-3-benzazepine (SCH-23390)], $3 \mu \mathrm{g} / 0.5 \mu \mathrm{l}$ ), all dissolved in $50 \% \mathrm{DMSO} / 50 \% 0.15 \mathrm{M}$ saline (each dose refers to the final mixture concentration). The combination of all drugs into a single mixture minimized the number of microinjections needed, avoiding subsequent neural damage around the microinjection tip, and ensured that the same local site was equally exposed to all drugs. A third condition was vehicle control: microinjection of the 50/50\% mixture of DMSO and $0.15 \mathrm{M}$ saline used to dissolve drugs but without any drug content. Each rat received DNQX, mixture, or vehicle microinjections in counterbalanced order in three separate tests spaced $48 \mathrm{~h}$ apart. As an additional control to assess effects of dopamine antagonists by themselves and the addition of DMSO to a vehicle, an additional control group ( $n=12$ rats) received microinjections in counterbalanced order of either the vehicle mixture alone ( $50 \% \mathrm{DMSO} / 50 \% 0.15 \mathrm{M}$ saline), pure $0.15 \mathrm{~m}$ saline vehicle, the $\mathrm{D}_{1} / \mathrm{D}_{2}$ dopamine antagonist mixture without DNQX (raclopride, $5 \mu \mathrm{g}$ and SCH-23390, $3 \mu \mathrm{g} / 0.5 \mu \mathrm{l}$ dissolved in 50\% DMSO/50\% $0.15 \mathrm{M}$ saline), or DNQX alone ( $450 \mathrm{ng} / 0.5 \mu)$. The $\mathrm{D}_{1} / \mathrm{D}_{2}$ antagonist mixture by itself was tested to verify that it did not markedly suppress food intake below vehicle control level, and so rule out simple behavioral suppression as an explanation for dopamine/glutamate interaction effects. The two vehicles were compared with ensure that adding DMSO to a $\mathrm{NaCl}$ vehicle produced no detectable behavioral effects of its own. Finally, DNQX was included for the control group as a positive standard to confirm elicitation of motivated behaviors at microinjection sites, comparable with the primary test group. This design allowed comparison of many microinjection substances while keeping the number of microinjections per rat to no more than three or four.

All solutions were closely inspected to confirm absence of precipitation, and $\mathrm{pH}$ was maintained between 4.6 and 5.8. Microinjection cannulas (29 gauge) extended $2.0 \mathrm{~mm}$ beyond the ventral tip of the guide, and were attached to a syringe pump via PE-20 tubing. Rats were gently hand held while they were bilaterally infused with a microinjection volume of $0.5 \mu \mathrm{l}$ at a rate of $0.30 \mu \mathrm{l} / \mathrm{min}$. After infusion, the injectors remained in place for an additional $60 \mathrm{~s}$ to allow for drug diffusion before their withdrawal and replacement of the obturators. Each rat was placed immediately afterward in a test chamber described below. Microinjections were administered for each rat in counterbalanced order in separate tests spaced $48 \mathrm{~h}$ apart.

Behavioral tests of fear and feeding. After $3 \mathrm{~d}$ of handling, rats were habituated to the test chambers for 3 consecutive days before microinjections, and then received a vehicle microinjection on the last day of habituation. On a test day, rats received one of the microinjection conditions described above (DNQX, DA antagonists, mixture, vehicle) and were immediately placed in a transparent test chamber for behavioral testing. The floor was covered with granular bedding (crushed corn cob) spread $3 \mathrm{~cm}$ deep (to support defensive treading behavior), and the chamber contained a dish of preweighed food chow pellets $(\sim 20 \mathrm{~g})$ and a water spout (to support eating and drinking behaviors). Spontaneous behavior was videotaped for $60 \mathrm{~min}$ for subsequent off-line analysis (Reynolds and Berridge, 2002, 2003). Motivated behaviors stimulated by DNQX are typically directed toward appropriate stimuli in the environment. Appetitive behavior is directed to food pellets or a water spout in the chamber. Defensive treading behavior is typically directed toward light-reflecting corners and the most exposed transparent wall of the 
chamber, which faces the experimenter, camera, and outside lights. Experimenters, open room, and glittering corners appear to be the most threatening stimuli in the chamber, and perhaps for that reason are most defended against by vigorous defensive treading behavior stimulated by DNQX or related microinjections (Reynolds and Berridge, 2002, 2003). Defensive treading stimulated by DNQX microinjection in caudal shell therefore often has the result of building a mound of granular bedding placed in corners or between the rat and the transparent wall that reveals the outside experimenter (Reynolds and Berridge, 2002, 2003). The videotaped behavior of each rat was scored in a slow-motion analysis of eating, defensive treading, and other behaviors by an experimenter who was blind to drug treatment. Behavior was analyzed for cumulative time (seconds) spent in (1) eating, (2) drinking, (3) defensive treading, (4) grooming, (5) burrowing (insertion of head under corn-cob bedding, with downward and forward thrust), (6) burrow treading (combination of burrowing head thrust and paw-treading movements), (7) rearing, (8) locomotion (crossing of lines that divide six grid squares superimposed on floor of test chamber). For descriptions of each behavior see the studies by Reynolds and Berridge (2003) and Smith and Berridge (2005).

Histology. After the completion of testing, rats were deeply anesthetized with sodium pentobarbital. Brains of rats used for behavioral tests were removed and fixed in $10 \%$ paraformaldehyde overnight and then cryoprotected in $20 \%$ sucrose for at least 2 d. Brains were coronally sectioned $(60 \mu \mathrm{m})$ mounted on slides and stained with cresyl violet. Cannula placements were mapped onto drawings of an atlas (Paxinos and Watson, 2004). NAcc shell begins at $\sim+3 \mathrm{~mm}$ bregma and ends at $\sim+0.48 \mathrm{~mm}$ bregma in the atlas, which determines the rostral-half/ caudal-half boundary at $\sim+1.74 \mathrm{~mm}$ bregma. Because the atlas plates are drawn at +1.8 and $+1.68 \mathrm{~mm}$, we considered a cannula placement to be caudal if it was located from $+1.68 \mathrm{~mm}$ bregma to $+0.48 \mathrm{~mm}$, and to be rostral if it was located from +1.8 to $+3 \mathrm{~mm}$ bregma.

Fos-like protein immunohistochemistry. Rats used for Fos plume assessment were perfused transcardially $90 \mathrm{~min}$ after bilateral DNQX, $\mathrm{D}_{1} / \mathrm{D}_{2}$ antagonists, mixture, or vehicle microinjections. Local Fos activation was examined by immunohistochemistry and immunofluorescence (Reynolds and Berridge, 2008). Brains were removed and placed in $4 \%$ formaldehyde overnight and then transferred to $30 \%$ sucrose. Two adjacent series of $40 \mu \mathrm{m}$ sections were sliced through the coronal plane with a sliding microtome and stored in $0.1 \mathrm{M}$ sodium phosphate buffer (SPB), $\mathrm{pH}$ 7.4. Alternate series of sections were processed for immunofluorescence (for Fos plume quantification because this produced near-zero background levels of nonspecific binding) and immunoperoxidase (for anatomical localization of Fos plume). For immunofluorescence processing, sections were immersed in succession with gentle agitation and intervening rinses in SPB-Triton containing (1) 5\% normal donkey serum (NDS) for $30 \mathrm{~min}$, (2) 5\% NDS and goat anti-c-Fos (1:500) overnight at $4^{\circ} \mathrm{C}$, (3) $5 \%$ NDS, and (4) 5\% NDS and donkey anti-goat Alexa Fluor 488 (excitation, $488 \mathrm{~nm}$; emission, $519 \mathrm{~nm}$; Invitrogen) for $1 \mathrm{~h}$. Sections were then mounted, air dried, and coverslipped with ProLong Gold antifade reagent (Invitrogen). Immunoperoxidase processing was similar to that used in previous studies (Peciña and Berridge, 2005; Smith and Berridge, 2005, 2007).

Fos plume identification. Fos-like immunoreactivity was visualized using a Leica microscope equipped for both brightfield and fluorescence microscopy. A filter with an excitation band at $480-505$ and an emission band at $505-545$ were used for fluorescence visualization. Plumes were identified from immunofluorescence-processed sections (Peciña and Berridge, 2000; Smith and Berridge, 2005). The Fos plume was typically maximal just caudal to the track of tissue damage (because guide cannulas were implanted from a slightly rostral approach angle, with mouth bar elevated, to avoid track penetration of the lateral ventricles). Fos-labeled cells were individually counted within sample squares $(68 \times 68 \mu \mathrm{m})$ along each of eight radial arms emanating from the center of the microinjection $\left(0^{\circ}, 45^{\circ}, 90^{\circ}, 135^{\circ}, 180^{\circ}, 225^{\circ}, 270^{\circ}, 315^{\circ}\right)$ with $5-10 \times$ magnification. Drug-induced Fos plumes were assessed against baseline Fos densities collected from cannulas sites that had received vehicle microinjections (vehicle microinjection baseline).

Mapping procedure for microinjection behavioral effects. Maps for localization of function were constructed by first computing average radius and volumes of Fos plumes, and then using comparably sized symbols to depict the magnitude of behavioral effects on eating behavior and defensive behavior produced by a drug microinjection at each site (Peciña and Berridge, 2005; Smith and Berridge, 2005, 2007). The behavioral effect for each drug condition (DNQX, mixture, $D_{1} / D_{2}$ antagonists) was calculated as a difference score for an individual rat compared with control magnitude after vehicle microinjection at the same site in the same rat. The two bilateral microinjection sites were mapped for each rat, collapsed into a single plane. We chose the sagittal plane to map functions because a sagittal view allows the entire rostrocaudal extent and entire dorsoventral extent of medial shell to be viewed on a single atlas map (Reynolds and Berridge, 2001; Paxinos and Watson, 2004).

Statistical analysis. Effect of drug conditions on each behavior at rostrocaudal levels of shell were assessed using a one factor (drug) repeatedmeasure or a two-factor mixed within- and between-subject ANOVA (drug $X$ anatomical levels, rostral or caudal). When a significant main effect was found, additional analysis was done using a one-way ANOVA

\section{Results}

\section{Fos plume analysis of local impact}

Fos plumes were used as a tool to map the spread of drug impact on neuronal function immediately around the microinjection site. This mapping tool provides objective information on where a microinjection directly influences gene transcription/translation in local neurons and where its influence ends. DNQX (450 ng) quadrupled local Fos expression over vehicle levels in an $\sim<0.08 \mathrm{~mm}^{3}$ volume plume center of the microinjection site, which was surrounded by less intense doubling of Fos expression in a larger plume halo of $\sim 3.9 \mathrm{~mm}^{3}$ volume (Fig. 1). Addition of $\mathrm{D}_{1} / \mathrm{D}_{2}$ antagonists to the mixture containing DNQX markedly reduced the volume and intensity of Fos plumes. By themselves, microinjections of $\mathrm{D}_{1} / \mathrm{D}_{2}$ antagonists induced only small and faint Fos plumes, just slightly above control vehicle microinjection levels (supplemental Fig. 1, available at www.jneurosci.org as supplemental material).

That is, in a typical Fos plume, pure DNQX intensely stimulated Fos to more than four times above vehicle control levels in an intense inner center of $0.267 \mathrm{~mm}$ radius $\pm 0.042 \mathrm{~mm}$ SEM (corresponding to $0.08 \mathrm{~mm}^{3}$ spherical volume; volume, $4 / 3 \pi$ radius $^{3}$ ). The intense center was surrounded by an intermediate halo with a $0.528 \mathrm{~mm}$ radius $( \pm 0.068)$ of more than three times Fos elevation over vehicle $\left(0.6 \mathrm{~mm}^{3}\right.$ sphere volume), and by an outer halo with a $0.978 \mathrm{~mm}$ radius $( \pm 0.122)$ of more than two times Fos elevation $\left(3.9 \mathrm{~mm}^{3}\right.$ sphere volume). We note that these 450-ng-dose DNQX plumes were larger than those produced by a lower 250 ng DNQX dose in a recent study that used otherwise similar microinjections (Reynolds and Berridge, 2008), with a center radius here twice that of the previous lower dose (producing a center volume approximately seven times greater), and an outer radius $\sim 30 \%$ longer (producing an outer volume roughly twice as great) for a $450 \mathrm{ng}$ dose than for the previous $250 \mathrm{ng}$ dose. By comparison, adding $\mathrm{D}_{1} / \mathrm{D}_{2}$ dopamine antagonists to DNQX microinjections shrunk the centers and middles of mixture plumes to under one-half the size of pure-DNQX plumes (center radius, $0.1 \mathrm{~mm}$; volume, $0.004 \mathrm{~mm}^{3}$; middle radius, $0.26 \mathrm{~mm}$; volume, $0.03 \mathrm{~mm}^{3}$ ), and shrunk the outer plume radius by $30 \%$ $(0.6 \mathrm{~mm})$ and the total outer volume $\left(0.9 \mathrm{~mm}^{3}\right)$ to under onefourth the size of pure DNQX levels. Finally, $D_{1} / D_{2}$ dopamine antagonists by themselves produced small faint plumes that reached only $0.4 \mathrm{~mm}^{3}$ outer volume. Plume symbols on maps were scaled to match the size of DNQX-induced Fos plumes, with corresponding centers of $0.53 \mathrm{~mm}$ in diameter and surrounding halos of 1-2 mm in diameter, and color coded to show behavioral effects evoked at each site (Figs. 2, 4). 
AMPA/kainate receptor blockade in the shell elicited rostrocaudal gradient of eating versus defensive treading behaviors

DNQX microinjections elicited robust fearful versus feeding behaviors along a rostrocaudal anatomical gradient in medial shell of the nucleus accumbens, compatible with previous findings: caudal sites generated fearful defensive treading behavior and rostral sites generated appetitive eating behavior (Reynolds and Berridge, 2003, 2008) (site $\times$ drug interaction, $F_{(1,21)}$ $=5.587 ; p=0.028$ ) (Figs. $2-4)$. The addition of a dopamine-blocking mixture of $\mathrm{D}_{1}$ and $\mathrm{D}_{2}$ antagonists to the same microinjection completely blocked DNQXgeneration of any increases in either appetitive/consummatory behaviors or defensive/fearful behaviors. Thus, no rostrocaudal gradient was detectable after dopamine blockade, and DNQX failed to increase motivated behaviors of any type in the absence of local dopamine neurotransmission. Finally, isotonic saline and $\mathrm{DMSO} /$ saline vehicles never significantly altered any motivated or locomotor behavior [defensive treading, eating, drinking, intake, rearing, locomotion; all $F_{(1,10)}<1$, not significant (ns)], and so were always similar to each other in lacking behavioral effects (Fig. 3).

\section{Rostral DNQX alone: eating induced by AMPA glutamate receptor blockade}

Rostral microinjections of DNQX more than tripled food intake (average of $5.2 \pm 0.52 \mathrm{~g}$ SEM instead of $1.46 \pm 0.57 \mathrm{~g}$ SEM under vehicle) and more than doubled the duration of time spent in eating behavior (average of $795 \pm 123$ s SEM instead of $295 \pm$ $117 \mathrm{~s}$ SEM under vehicle; duration, $F_{(1,21)}=6.555, p=0.018$; intake in grams, $F_{(1,21)}=12.487, p=0.002$; sites rostral to +1.8 $\mathrm{mm}$ bregma). Rostral stimulation of eating appeared especially potent at dorsal sites in the rostral half of medial shell, compared with more ventral sites (Fig. 2). In contrast, DNQX microinjections at sites caudal to $+1.0 \mathrm{~mm}$ bregma either decreased eating or failed to change eating behavior (rostral vs caudal, duration, $F_{(1,22)}=11.697, p=0.003$; intake in grams, $F_{(1,22)}=7.383, p=$ $0.013)$.

\section{Dopamine antagonists prevent rostral elicitation of appetitive eating}

Adding dopamine antagonists to the microinjection containing DNQX (referred to throughout as the mixture condition) completely blocked the increase in eating behavior normally produced by DNQX by itself (DNQX with dopamine antagonists vs DNQX alone: eating duration, $F_{(1,21)}=7.231, p=0.014$; food intake, $F_{(1,21)}=11.163, p=0.003$ ) (Figs. $2-4$ ). Microinjections of the DA-AMPA antagonist mixture in the nucleus accumbens shell produced no change in food intake compared with vehicle condition (eating duration, $F_{(1,21)}=0.240$, ns; food intake, $F_{(1,21)}$ $=0.904, \mathrm{n} . \mathrm{s})$. The mixture failed to change eating duration or intake amount even at rostral sites, compared with vehiclecontrol levels (eating duration, $F_{(1,8)}=1.713, p=0.227$; food intake, $\left.F_{(1,8)}=1.571, p=0.245\right)$, and there was no drug by site
DNQX minus mixture reduction

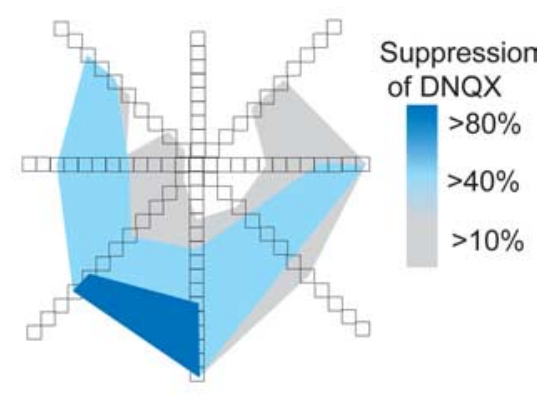

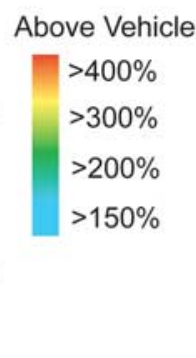

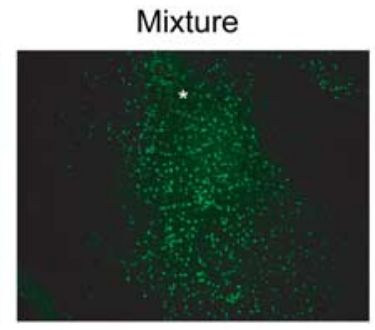

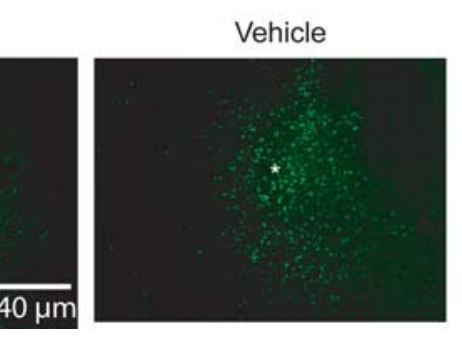

$340 \mu \mathrm{m}$

roinjection of DNQX, relative to vehicle (top Figure 1. Colored plume maps show average local elevations of Fos caused by microinjection of DNQX, relative to vehicle (top
left). DNQX caused robust plumes of up to a $4 \mathrm{~mm}^{3}$ volume, elevated 200 to $400 \%$ above vehicle levels. The DNQX minus mixture reduction map (top right) shows the average suppression of DNQX-induced Fos caused by addition of DA antagonists to same microinjection. Examples of Fos plumes produced by DNQX, vehicle, and mixture microinjections are shown in photomicrographs (bottom left, center, and right, respectively). Stars denote placements of cannula tips.

interaction (eating in seconds, $F_{(1,21)}=2.603$, ns; eating in grams, $F_{(1,21)}=1.189$, n.s).

Results from the additional control group indicated that microinjection of the $\mathrm{D}_{1} / \mathrm{D}_{2}$ dopamine antagonists alone did not suppress spontaneous eating behavior below vehicle levels in the absence of DNQX at either caudal sites (eating duration, $F_{(1,4)}=$ 2.054, ns; food intake, $F_{(1,4)}=1.643$, ns) or rostral sites (eating duration, $F_{(1,6)}<1$, ns; food intake, $F_{(1,6)}=1.064$, ns) (Fig. 3). Failure of dopamine blockade in shell by itself to prevent eating is consistent with previous reports that microinjection of SCH23390 or raclopride in the medial accumbens does not suppress food intake (Baldo et al., 2002) or powerfully suppress global activity (Yun et al., 2004). It suggests that dopamine antagonist microinjections did not simply reduce the ability to perform eating movements or to consume food. Rather than simply making rats unable to exhibit motivated behaviors because of motor incapacity or sedation, local dopamine blockade instead appeared to prevent DNQX from generating intense appetitive eating or defensive treading behaviors, in accordance with the dopamineglutamate modulation hypothesis.

\section{Caudal DNQX alone: defensive treading induced by AMPA glutamate receptor blockade}

DNQX microinjections produced more than a 10 -fold increase over vehicle control levels in fearful patterns of defensive treading at medial shell sites caudal to $+1.4 \mathrm{~mm}$ bregma, following a rostrocaudal gradient for defensive behavior in the nucleus accumbens shell (Reynolds and Berridge, 2003) (DNQX, $25.2 \pm$ $9.5 \mathrm{~s}$ SEM, vs vehicle, $\left.1.9 \pm 0.5 \mathrm{~s} \mathrm{SEM;} F_{(1,13)}=6.533, p=0.024\right)$ (Figs. 2-4). The amount of defensive treading was also 10 times greater after DNQX in caudal sites than in rostral sites in medial shell (DNQX, $0.18 \pm 0.13$ s SEM; vehicle, $0.53 \pm 0.32$ s SEM; caudal vs rostral; $\left.F_{(1,22)}=4.698, p=0.042\right)$. Caudal stimulation of defensive treading behavior by DNQX appeared especially po- 
A.

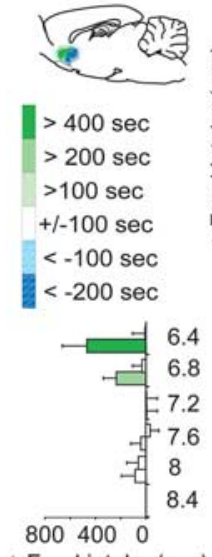

$\Delta$ Food intake (sec)

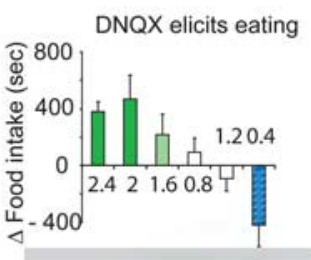

B.

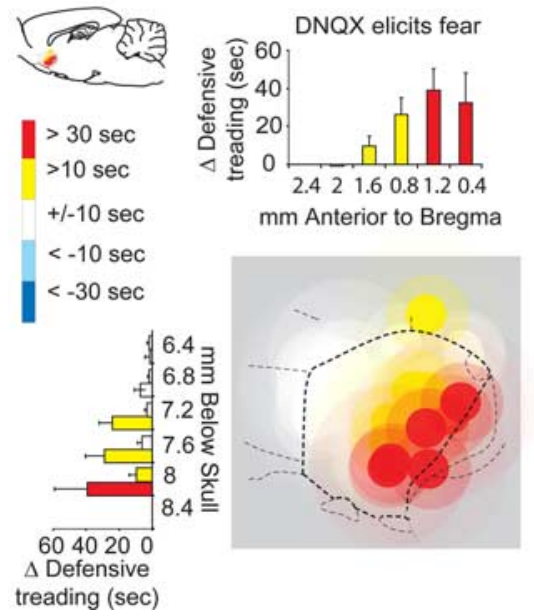

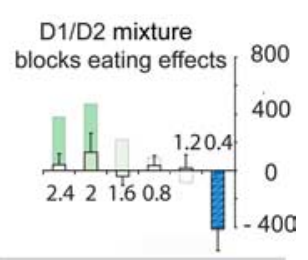

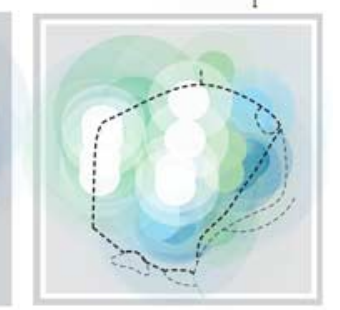

A) Food intake (sec)

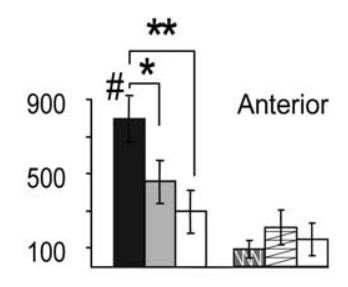

B) Defensive treading (sec)

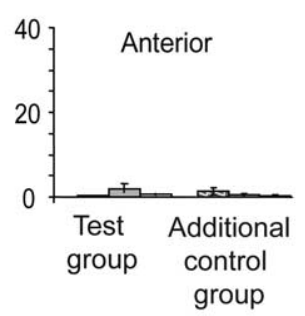

D1/D2 mixture blocks fear effects 60

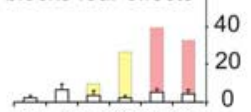

$2.42 \quad 1.60 .81 .20 .4$

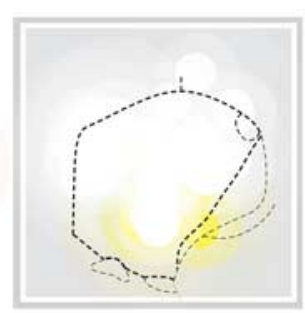

Figure 2. $A, B$, Fos plume maps of appetitive eating behavior versus fearful defensive treading behavior generated by DNQX and mixture microinjections. Each plume-sized circle represents color-coded behavioral effects of DNQX or mixture at that site, compared with vehicle control levels at same site in the same rat (expressed by the color scale as a change score). Left maps show the behavioral effects of pure DNQX microinjections. Right maps show the effects of mixture microinjections ( $D_{1}$ antagonist plus $D_{2}$ antagonist plus DNQX). $A$, Appetitive behavior (food intake). $\boldsymbol{B}$, Fearful behavior (defensive treading). Histograms above or next to graphs represent rostrocaudal or dorsoventral levels showing the mean behavioral effects produced by microinjections at each level (expressed as a change score from vehicle microinjection at the same site in the same rat; +SEM). Sagittal sections are adapted from Paxinos and Watson (2004).

tent at ventral sites in the caudal half of medial shell, compared with more dorsal sites (Fig. 2).

\section{Dopamine antagonists prevent caudal elicitation of fear}

Adding the dopamine $\mathrm{D}_{1}$ and $\mathrm{D}_{2}$ antagonists to the DNQX microinjection blocked all increases in defensive treading behavior normally produced by DNQX alone at local sites in caudal shell $\left(F_{(1,13)}=5.044 ; p=0.043\right)$, just as dopamine blockade had blocked appetitive behavior in rostral shell (Figs. 2-4). Even at far caudal sites in medial shell, microinjections of the combined antagonist mixture in the nucleus accumbens shell produced no more defensive treading behavior than vehicle microinjections $\left(F_{(1,13)}=3.759 ; p=0.075\right)$. Thus, there was no rostrocaudal difference in defensive treading performance after mixture microinjection $\left(F_{(1,22)}=1.902 ; p=0.182\right)$, no increase over vehicle control levels $\left(F_{(1,21)}=3.885 ; p=0.062\right)$, and no interactions
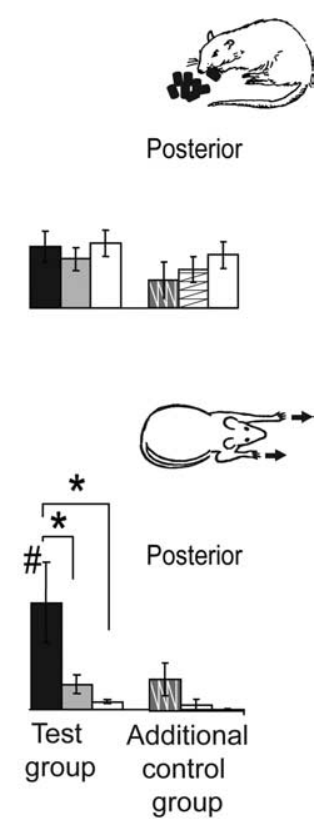

DNQX $\square$ Mixture (DNQX + D1/D2 Antagonists)
$\square$ Vehicle (DMSO/Saline): Test group $\square$
Additional control group $⿴$

W D1/D2 Antagonists alone $\square$ Saline vehicle alone

Figure 3. $\quad \boldsymbol{A}, \boldsymbol{B}$, Magnitude of increases in food intake $(\boldsymbol{A})$ and defensive treading $(\boldsymbol{B})$ behaviors elicited by DNQX, mixture, dopamine antagonists alone, or vehicle microinjections in the anterior and posterior halves of the medial shell of the nucleus accumbens. Data are shown from both the primary test group [DNQX, mixture (DNQX plus dopamine antagonist), and DMSO/ saline vehicle] and an additional control group (dopamine antagonists alone, DMSO/saline vehicle, pure saline vehicle. ${ }^{*} p<0.05 ;{ }^{* *} p<0.01 ;{ }^{\sharp} p<0.05$, anterior versus posterior. Error bars indicate SEM.

between drug and sites $\left(F_{(1,21)}=0.837 ; p=0.371\right)$. Further results from the additional control group indicated, similar to eating results, that dopamine antagonists by themselves in the absence of DNQX did not alter spontaneous defensive treading behavior significantly from vehicle levels at any site, whether in rostral shell $\left(F_{(1,6)}=2.356, \mathrm{~ns}\right)$ or caudal shell $\left(F_{(1,4)}=1.402, \mathrm{~ns}\right)$ (Fig. 3).

\section{Other behaviors}

DNQX at caudal sites also induced locomotion, such as crossing of grid squares in the chamber $\left(F_{(1,13)}=9.701 ; p=0.008\right)$, but not at rostral sites $\left(F_{(1,8)}<1, \mathrm{~ns}\right)$. Conversely, DNQX at rostral sites suppressed rearing behavior $\left(F_{(1,8)}=5.858 ; p=0.042\right)$. DNQX had no effects on other general activity behaviors measured or on drinking $(F$ values $<1)$. Addition of DA antagonists blocked the DNQX-increase in locomotor crossing $\left(F_{(1,13)}=\right.$ 8.834; $p=0.011)$. However, addition of DA antagonists to DNQX did not reduce motor locomotion crossing $(F<1)$ or burrowing behavior $\left(F_{(1,21)}=2.2, \mathrm{~ns}\right)$ below vehicle control levels, again consistent with the idea that dopamine antagonist microinjections did not simply make rats unable to engage in behaviors.

\section{Anatomical control sites}

Outside of the medial shell, at control sites dorsal or rostral to shell in cingulate cortex, lateral septal nucleus, or near the ventral tip of the corpus callosum (dorsal tenia tectum and navicular 


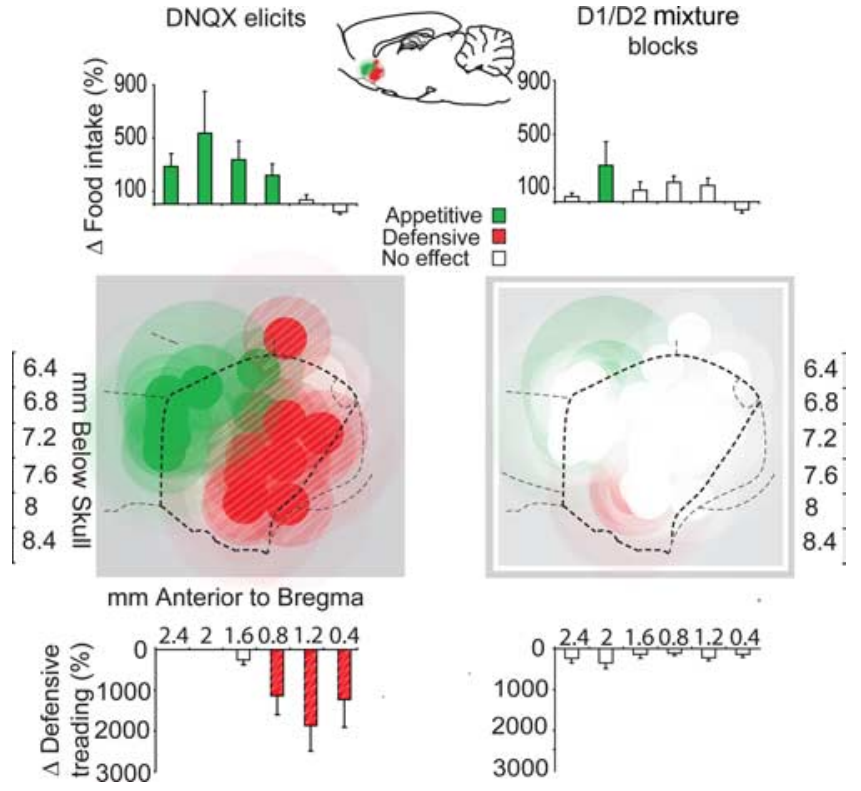

Figure 4. Summary map of "desire versus dread" motivations produced by microinjections of DNQX versus mixture $\left(D_{1} / D_{2} / D N Q X\right)$. Appetitive eating behavior (green symbols) was stimulated by DNQX microinjections in the rostral shell, whereas fearful defensive treading was elicited by caudal DNQX microinjections (red symbols; criteria for including a DNQX site was a $>9$ min increase in eating duration plus a $>200 \%$ increase in food intake for appetitive effects, and $>20$ s duration and $>400 \%$ increase in defensive treading behavior; both compared with vehicle microinjection at same site). Histogram bars express the percentage change in behaviors from vehicle levels [eating duration (in minutes); defensive treading duration (in seconds)]. Addition of $D_{1}$ and $D_{2}$ receptor antagonists in the mixture condition blocked the ability of $D N Q X$ to generate either eating or defensive behavior at most sites (right).

nucleus) (Paxinos and Watson, 2004), DNQX produced no changes in either defensive behavior $(F<1)$ or appetitive behavior (food intake, $F_{(1,5)}=1.29$, ns; eating duration, $F<1$; drinking intake, $F_{(1,5)}=2.73$, ns). Similarly, DNQX at control sites had no effect on other motor behaviors measured here (locomotor grid crossing, $F_{(1,5)}=3$; burrowing and grooming, $F_{(1,5)}=4.31$, ns).

\section{Discussion}

Microinjection of the AMPA/kainate glutamate receptor antagonist (DNQX) by itself in the medial shell of nucleus accumbens robustly generated eating or fearful behaviors along a rostrocaudal gradient, consistent with a keyboard organization of glutamatergic desire versus fear based on anatomical placement (Reynolds and Berridge, 2003, 2008). Microinjections of DNQX disrupted glutamate signaling in "keys" sized between $0.1-4$ $\mathrm{mm}^{3}$, as indicated by Fos plume center volumes of $0.08 \mathrm{~mm}^{3}$ and halo volumes of $3.9 \mathrm{~mm}^{3}$. In the rostral shell, disruptions elicited robust appetitive eating behavior and food intake. Conversely, in the caudal shell, the same local glutamate disruptions elicited robust defensive treading behavior and suppressed food intake. Rostrocaudal keyboard organization of glutamate-related generators of appetitive behavior versus defensive behavior is consistent with other evidence suggesting anatomical heterogeneity or localization of affective function within the medial shell (Peciña and Berridge, 2000; Liberzon et al., 2003; Smith and Berridge, 2005; Aragona et al., 2006; Kerfoot et al., 2007; Mahler et al., 2007; Britt and McGehee, 2008).

Addition of $D_{1}$ and $D_{2}$ receptor antagonists to the same microinjection mixture completely blocked the ability of DNQX to generate either eating behavior or defensive treading behavior. These new results are consistent with previous report that sys- temic $\mathrm{D}_{1}$ and $\mathrm{D}_{2}$ dopamine receptor antagonists reduce eating behavior otherwise stimulated by DNQX microinjection in the nucleus accumbens (Maldonado-Irizarry et al., 1995). They show further that the dopamine and glutamate blockade interaction can occur at the same site or local circuit in medial shell, and that the interaction applies to fearful behavior as well as appetitive behavior (both generated according to keyboard position along the rostrocaudal gradient). Together with the failure of SCH2330 and raclopride microinjections to markedly suppress food intake by themselves here and in other studies (Baldo et al., 2002; Mikhailova, 2003), the ability of dopamine blockade to prevent DNQX from inducing motivated behaviors here appears to reflect a need for local dopamine receptor stimulation in order for local AMPA glutamate disruption to stimulate either appetitive motivation or fearful motivation. It remains to be clarified whether $D_{1}$-type versus $D_{2}$-type receptor stimulation is primarily responsible for dopamine contributions to this effect, or whether $D_{1}$ versus $D_{2}$ receptors play similar roles in both appetitive versus defensive stimulation by DNQX (and at all points along the rostrocaudal gradient), although we note that that $\mathrm{D}_{2}$ receptors have been especially implicated in defensive behavior (Puglisi-Allegra and Cabib, 1988; de Oliveira et al., 2006).

\section{Interaction between dopamine blockade and glutamate disruption}

More information is needed on the mechanism of interaction between disruptions of dopamine and glutamate signals. A remaining puzzle is whether dopamine receptor blockade acts by altering firing within the local circuit immediately impacted by DNQX. That is, activation of NMDA receptors alone might not cause neuronal firing after AMPA blockade if NMDA receptors do not allow current flow at negative potentials; similarly, dopamine receptor activation is unlikely to excite spiny neurons after AMPA blockade and, therefore, adding the two blockades together might not further suppress local firing. Anatomical diffusion of effects could contribute to mixture blockade if drugs spread differentially, or if the generation of appetitive or fearful behaviors by hyperpolarizing microinjections involved spatial interactions such as lateral disinhibition of neighboring local circuits. Still, it seems unlikely that dopamine and glutamate antagonists diffused far given the tight containment of each Fos plume within a few cubic millimeters of the medial shell (and under one-tenth of a cubic millimeter for the Fos-quadrupled center). Additional research will be needed to understand how glutamate and dopamine signals interact to allow blockades to alter relevant local circuits that control motivated behaviors.

Dopamine is often viewed as a neurobiological modulator of corticolimbic glutamate circuits in that it gates glutamate signals in nucleus accumbens from prefrontal cortex, hippocampus, amygdala, and thalamus (Groenewegen et al., 1980; Sesack et al., 1989; Everitt et al., 1991; McDonald, 1991; Mulder et al., 1998; Cardinal et al., 2002). Dopamine might help select one signal at the expense of others, in part by amplifying strong glutamate input to neurons in an up state, and reducing input impact to cells in a down state (Pennartz et al., 1994; Kiyatkin and Rebec, 1996; Horvitz, 2002; West and Grace, 2002; Kalivas, 2004). For example, dopamine has been suggested to act on $\mathrm{D}_{2}$ receptors in striatum to reduce glutamate release (Yamamoto and Davy, 1992; Surmeier et al., 2007), and on $D_{1}$ receptors to enhance NMDA-stimulated currents and AMPA receptor recruitment (Surmeier et al., 2007; Sun et al., 2008) and to regulate the balance among anatomical inputs to nucleus accumbens, shifting weights from prefrontal cortex to limbic hippocampal inputs (Grace et 
al., 2007). Extracellular levels of dopamine in nucleus accumbens are increased by microinjection of glutamate receptor antagonists in the shell (Taber and Fibiger, 1997), suggesting that our DNQX microinjection could lead to dopamine release inside nucleus accumbens shell as part of the mechanism for generating appetitive or defensive behaviors. In the present study, motivated behaviors were induced by selective blockade of AMPA/kainate glutamate receptors at valence-coded locations. Local inhibition of the medial shell has been suggested to evoke motivated behavior via release of neurons in target structures downstream, such as lateral hypothalamus, ventral pallidum, etc., from inhibitory GABAergic suppression (Kelley et al., 2005).

\section{Mesocorticolimbic mechanisms of appetitive versus fearful motivation}

These results show for the first time that dopamine modulates both appetitive- and fear-motivated behaviors elicited by local disruptions of glutamate signaling, in an anatomically separable or keyboard manner within nucleus accumbens. That is, dopamine may interact with the rostrocaudal valence biases of local glutamate circuits in medial shell. This may help explain how mesolimbic dopamine can be involved in opposite motivated behaviors of both positive and negative valence (Salamone et al., 1994; Maldonado-Irizarry et al., 1995; Berridge and Robinson, 1998; Gray et al., 1999; Levita et al., 2002; Kapur, 2003; Schultz, 2007). Heterogeneous patterns of dopamine release may occur across nucleus accumbens subregions (Wightman et al., 2007), which might also contribute to the ability of external factors (such as stressful noise and light versus comfortable home-like situations) to retune the rostrocaudal glutamatergic keyboard, in ways that shift the positions of appetitive-fearful valence boundaries in medial shell (Reynolds and Berridge, 2008).

If dopamine enhanced glutamate signals at locations with valence biases, it might amplify the attribution of valenced motivational salience to related events in the external world. We suggest that microinjection of DNQX interacts in this way with dopamine and glutamate circuits inside the shell, which tag external stimuli with motivational salience of either positive or negative valence to elicit motivated behavior. Rostral disruptions of glutamate circuits in medial shell are biased toward generating positive incentive salience that makes tagged stimuli attractive to pursue or eat, whereas caudal circuits are biased toward negative or fearful salience, causing tagged stimuli to be defended against or avoided (Reynolds and Berridge, 2003). In both rostral and caudal sites, dopamine appears to be needed along with local glutamate disruptions to transform external stimuli into positive incentives or into fearful threats (Salamone et al., 1994; Berridge and Robinson, 1998; Levita et al., 2002; Jensen et al., 2007; Salamone et al., 2007).

We note that dopamine has been suggested previously to contribute in a related way to pathological exaggerations of fearful salience, as a motivational component of paranoia in human schizophrenia (Kapur and Mamo, 2003; Kapur, 2004; Barch, 2005; Taylor et al., 2005; Schmidt and Beninger, 2006; Jensen et al., 2007). Dopamine involvement in the localized valence-biased glutamate circuits in the medial shell described here seems a possible mechanism for the generation of pathologically excessive fear in such pathological conditions, as well as for excessive "wanting" for rewards in conditions such as addiction.

\section{Conclusion}

Local dopamine blockade prevented glutamate disruption in the same $0.1-4 \mathrm{~mm}^{3}$ sphere of the medial shell from generating positive incentive salience or negative fearful salience in a rostrocaudal keyboard manner. Our results suggest that dopamine is needed for blockade of AMPA glutamate signals at separable locations in nucleus accumbens to tag external stimuli with either incentive salience or fearful salience. These results thus indicate that dopamine participates in parallel channels of mesocorticolimbic signals that are oppositely valenced to generate desire versus dread.

\section{References}

Aragona BJ, Liu Y, Yu YJ, Curtis JT, Detwiler JM, Insel TR, Wang Z (2006) Nucleus accumbens dopamine differentially mediates the formation and maintenance of monogamous pair bonds. Nat Neurosci 9:133-139.

Baldo BA, Sadeghian K, Basso AM, Kelley AE (2002) Effects of selective dopamine D1 or D2 receptor blockade within nucleus accumbens subregions on ingestive behavior and associated motor activity. Behav Brain Res 137:165-177.

Barch DM (2005) The relationships among cognition, motivation, and emotion in schizophrenia: how much and how little we know. Schizophr Bull 31:875-881.

Basso AM, Kelley AE (1999) Feeding induced by GABA(A) receptor stimulation within the nucleus accumbens shell: regional mapping and characterization of macronutrient and taste preference. Behav Neurosci 113:324-336.

Berridge KC (2007) The debate over dopamine's role in reward: the case for incentive salience. Psychopharmacology (Berl) 191:391-431.

Berridge KC, Robinson TE (1998) What is the role of dopamine in reward: hedonic impact, reward learning, or incentive salience? Brain Res Brain Res Rev 28:309-369.

Blackburn JR, Pfaus JG, Phillips AG (1992) Dopamine functions in appetitive and defensive behaviours. Prog Neurobiol 39:247-279.

Britt JP, McGehee DS (2008) Presynaptic opioid and nicotinic receptor modulation of dopamine overflow in the nucleus accumbens. J Neurosci 28:1672-1681.

Cardinal RN, Parkinson JA, Hall J, Everitt BJ (2002) Emotion and motivation: the role of the amygdala, ventral striatum, and prefrontal cortex. Neurosci Biobehav Rev 26:321-352.

Chesselet MF (1984) Presynaptic regulation of neurotransmitter release in the brain: facts and hypothesis. Neuroscience 12:347-375.

Chuhma N, Zhang H, Masson J, Zhuang X, Sulzer D, Hen R, Rayport S (2004) Dopamine neurons mediate a fast excitatory signal via their glutamatergic synapses. J Neurosci 24:972-981.

Coss RG, Owings DH (1978) Snake-directed behavior by snake naive and experienced California ground squirrels in a simulated burrow. Z Tierpsychol J Comp Ethol 48:421-435.

de Oliveira AR, Reimer AE, Brandão ML (2006) Dopamine D2 receptor mechanisms in the expression of conditioned fear. Pharmacol Biochem Behav 84:102-111.

Everitt BJ, Morris KA, O’Brien A, Robbins TW (1991) The basolateral amygdala-ventral striatal system and conditioned place preference: further evidence of limbic-striatal interactions underlying reward-related processes. Neuroscience 42:1-18.

Grace AA, Floresco SB, Goto Y, Lodge DJ (2007) Regulation of firing of dopaminergic neurons and control of goal-directed behaviors. Trends Neurosci 30:220-227.

Gray JA, Kumari V, Lawrence N, Young AM (1999) Functions of the dopaminergic innervation of the nucleus accumbens. Psychobiology 27:225-235.

Groenewegen HJ, Becker NE, Lohman AH (1980) Subcortical afferents of the nucleus accumbens septi in the cat, studied with retrograde axonal transport of horseradish peroxidase and bisbenzimid. Neuroscience 5:1903-1916.

Horvitz JC (2000) Mesolimbocortical and nigrostriatal dopamine responses to salient non-reward events. Neuroscience 96:651-656.

Horvitz JC (2002) Dopamine gating of glutamatergic sensorimotor and incentive motivational input signals to the striatum. Behav Brain Res 137:65-74.

Jensen J, McIntosh AR, Crawley AP, Mikulis DJ, Remington G, Kapur S 
(2003) Direct activation of the ventral striatum in anticipation of aversive stimuli. Neuron 40:1251-1257.

Jensen J, Willeit M, Zipursky RB, Savina I, Smith AJ, Menon M, Crawley AP, Kapur S (2007) The formation of abnormal associations in schizophrenia: neural and behavioral evidence. Neuropsychopharmacology 33:473-479.

Kalivas PW (2004) Glutamate systems in cocaine addiction. Curr Opin Pharmacol 4:23-29.

Kalivas PW, Volkow ND (2005) The neural basis of addiction: a pathology of motivation and choice. Am J Psychiatry 162:1403-1413.

Kapur S (2003) Psychosis as a state of aberrant salience: a framework linking biology, phenomenology, and pharmacology in schizophrenia. Am J Psychiatry 160:13-23.

Kapur S (2004) How antipsychotics become anti-"psychotic"-from dopamine to salience to psychosis. Trends Pharmacol Sci 25:402-406.

Kapur S, Mamo D (2003) Half a century of antipsychotics and still a central role for dopamine D2 receptors. Prog Neuropsychopharmacol Biol Psychiatry 27:1081-1090.

Kelley AE, Baldo BA, Pratt WE, Will MJ (2005) Corticostriatalhypothalamic circuitry and food motivation: integration of energy, action and reward. Physiol Behav 86:773-795.

Kerfoot EC, Agarwal I, Lee HJ, Holland PC (2007) Control of appetitive and aversive taste-reactivity responses by an auditory conditioned stimulus in a devaluation task: a FOS and behavioral analysis. Learn Mem 14:581-589.

Kiyatkin EA, Rebec GV (1996) Dopaminergic modulation of glutamateinduced excitations of neurons in the neostriatum and nucleus accumbens of awake, unrestrained rats. J Neurophysiol 75:142-153.

Lawrence AD, Goerendt IK, Brooks DJ (2007) Impaired recognition of facial expressions of anger in Parkinson's disease patients acutely withdrawn from dopamine replacement therapy. Neuropsychologia 45:65-74.

Levita L, Dalley JW, Robbins TW (2002) Nucleus accumbens dopamine and learned fear revisited: a review and some new findings. Behav Brain Res 137:115-127.

Liberzon I, Phan KL, Decker LR, Taylor SF (2003) Extended amygdala and emotional salience: a PET activation study of positive and negative affect. Neuropsychopharmacology 28:726-733.

Mahler SV, Smith KS, Berridge KC (2007) Endocannabinoid hedonic hotspot for sensory pleasure: anandamide in nucleus accumbens shell enhances "liking" of a sweet reward. Neuropsychopharmacology 32:2267-2278.

Maldonado-Irizarry CS, Swanson CJ, Kelley AE (1995) Glutamate receptors in the nucleus accumbens shell control feeding behavior via the lateral hypothalamus. J Neurosci 15:6779-6788.

McDonald AJ (1991) Organization of amygdaloid projections to the prefrontal cortex and associated striatum in the rat. Neuroscience 44:1-14.

Meredith GE (1999) The synaptic framework for chemical signaling in nucleus accumbens. Ann NY Acad Sci 877:140-156.

Mikhailova MO (2003) Comparison of changes in glutamate levels in the nucleus accumbens of the rat brain during food consumption in conditions of blockade of dopamine D1 and D2 receptors. Neurosci Behav Physiol 33:431-434.

Mulder AB, Hodenpijl MG, Lopes da Silva FH (1998) Electrophysiology of the hippocampal and amygdaloid projections to the nucleus accumbens of the rat: convergence, segregation, and interaction of inputs. J Neurosci 18:5095-5102.

Palmiter RD (2007) Is dopamine a physiologically relevant mediator of feeding behavior? Trends Neurosci 30:375-381.

Paxinos G, Watson C (2004) The rat brain in stereotaxic coordinates, Ed 5. New York: Academic.

Peciña S, Berridge KC (2000) Opioid site in nucleus accumbens shell mediates eating and hedonic "liking" for food: map based on microinjection Fos plumes. Brain Res 863:71-86.

Peciña S, Berridge KC (2005) Hedonic hot spot in nucleus accumbens shell: where do $\mu$-opioids cause increased hedonic impact of sweetness? J Neurosci 25:11777-11786.

Pennartz CM, Groenewegen HJ, Lopes da Silva FH (1994) The nucleus accumbens as a complex of functionally distinct neuronal ensembles: an integration of behavioural, electrophysiological and anatomical data. Prog Neurobiol 42:719-761.
Puglisi-Allegra S, Cabib S (1988) Pharmacological evidence for a role of D2 dopamine receptors in the defensive behavior of the mouse. Behav Neural Biol 50:98-111.

Redgrave P, Prescott TJ, Gurney K (1999) Is the short-latency dopamine response too short to signal reward error? Trends Neurosci 22:146-151.

Reynolds SM, Berridge KC (2001) Fear and feeding in the nucleus accumbens shell: rostrocaudal segregation of GABA-elicited defensive behavior versus eating behavior. J Neurosci 21:3261-3270.

Reynolds SM, Berridge KC (2002) Positive and negative motivation in nucleus accumbens shell: bivalent rostrocaudal gradients for GABA-elicited eating, taste "liking"/“disliking" reactions, place preference/avoidance, and fear. J Neurosci 22:7308-7320.

Reynolds SM, Berridge KC (2003) Glutamate motivational ensembles in nucleus accumbens: rostrocaudal shell gradients of fear and feeding. Eur J Neurosci 17:2187-2200.

Reynolds SM, Berridge KC (2008) Emotional environments retune the valence of appetitive versus fearful functions in nucleus accumbens. Nat Neurosci 11:423-425.

Robbins TW, Everitt BJ (2007) A role for mesencephalic dopamine in activation: commentary on Berridge (2006). Psychopharmacology (Berl) 191:433-437.

Salamone JD, Cousins MS, McCullough LD, Carriero DL, Berkowitz RJ (1994) Nucleus accumbens dopamine release increases during instrumental lever pressing for food but not free food consumption. Pharmacol Biochem Behav 49:25-31.

Salamone JD, Correa M, Mingote SM, Weber SM (2005) Beyond the reward hypothesis: alternative functions of nucleus accumbens dopamine. Curr Opin Pharmacol 5:34-41.

Salamone JD, Correa M, Farrar A, Mingote SM (2007) Effort-related functions of nucleus accumbens dopamine and associated forebrain circuits. Psychopharmacology (Berl) 191:461-482.

Schmidt WJ, Beninger RJ (2006) Behavioural sensitization in addiction, schizophrenia, Parkinson's disease and dyskinesia. Neurotox Res $10: 161-166$.

Schultz W (2007) Behavioral dopamine signals. Trends Neurosci 30:203-210.

Scott DJ, Stohler CS, Egnatuk CM, Wang H, Koeppe RA, Zubieta JK (2007) Individual differences in reward responding explain placebo-induced expectations and effects. Neuron 55:325-336.

Sesack SR, Pickel VM (1990) In the rat medial nucleus accumbens, hippocampal and catecholaminergic terminals converge on spiny neurons and are in apposition to each other. Brain Res 527:266-279.

Sesack SR, Pickel VM (1992) Prefrontal cortical efferents in the rat synapse on unlabeled neuronal targets of catecholamine terminals in the nucleus accumbens septi and on dopamine neurons in the ventral tegmental area. J Comp Neurol 320:145-160.

Sesack SR, Deutch AY, Roth RH, Bunney BS (1989) Topographical organization of the efferent projections of the medial prefrontal cortex in the rat: an anterograde tract-tracing study with Phaseolus vulgaris leucoagglutinin. J Comp Neurol 290:213-242.

Smith KS, Berridge KC (2005) The ventral pallidum and hedonic reward: neurochemical maps of sucrose "liking" and food intake. J Neurosci 25:8637-8649.

Smith KS, Berridge KC (2007) Opioid limbic circuit for reward: interaction between hedonic hotspots of nucleus accumbens and ventral pallidum. J Neurosci 27:1594-1605.

Stratford TR, Kelley AE (1999) Evidence of a functional relationship between the nucleus accumbens shell and lateral hypothalamus subserving the control of feeding behavior. J Neurosci 19:11040-11048.

Sun X, Milovanovic M, Zhao Y, Wolf ME (2008) Acute and chronic dopamine receptor stimulation modulates AMPA receptor trafficking in nucleus accumbens neurons cocultured with prefrontal cortex neurons. J Neurosci 28:4216-4230.

Surmeier DJ, Ding J, Day M, Wang Z, Shen W (2007) D1 and D2 dopaminereceptor modulation of striatal glutamatergic signaling in striatal medium spiny neurons. Trends Neurosci 30:228-235.

Taber MT, Fibiger HC (1997) Feeding-evoked dopamine release in the nucleus, accumbens: regulation by glutamatergic mechanisms. Neuroscience 76:1105-1112.

Taylor SF, Phan KL, Britton JC, Liberzon I (2005) Neural response to emotional salience in schizophrenia. Neuropsychopharmacology 30:984-995. 
Treit D, Pinel JP, Fibiger HC (1981) Conditioned defensive burying: a new paradigm for the study of anxiolytic agents. Pharmacol Biochem Behav 15:619-626.

Ventura R, Morrone C, Puglisi-Allegra S (2007) Prefrontal/accumbal catecholamine system determines motivational salience attribution to both reward- and aversion-related stimuli. Proc Natl Acad Sci USA 104:5181-5186.

West AR, Grace AA (2002) Opposite influences of endogenous dopamine $\mathrm{D}_{1}$ and $\mathrm{D}_{2}$ receptor activation on activity states and electrophysiological properties of striatal neurons: studies combining in vivo intracellular recordings and reverse microdialysis. J Neurosci 22:294-304.

Wightman RM, Heien ML, Wassum KM, Sombers LA, Aragona BJ, Khan AS, Ariansen JL, Cheer JF, Phillips PE, Carelli RM (2007) Dopamine release is heterogeneous within microenvironments of the rat nucleus accum- bens. Eur J Neurosci 26:2046-2054.

Wise RA (2006) Role of brain dopamine in food reward and reinforcement. Philos Trans R Soc Lond B Biol Sci 361:1149-1158.

Wright CI, Groenewegen HJ (1995) Patterns of convergence and segregation in the medial nucleus accumbens of the rat: relationships of prefrontal cortical, midline thalamic, and basal amygdaloid afferents. J Comp Neurol 361:383-403.

Yamamoto BK, Davy S (1992) Dopaminergic modulation of glutamate release in striatum as measured by microdialysis. J Neurochem 58:1736-1742.

Yun IA, Nicola SM, Fields HL (2004) Contrasting effects of dopamine and glutamate receptor antagonist injection in the nucleus accumbens suggest a neural mechanism underlying cue-evoked goal-directed behavior. Eur J Neurosci 20:249-263. 